\title{
Neumatización del seno esfenoidal evaluada con tomografía computarizada de haz cónico
}

Pneumatization of the sphenoid sinus evaluated with cone beam computed tomography

\section{Sr. Editor:}

Actualmente el uso creciente de la tomografía computarizada de haz cónico en los diversos campos de la odontología es ampliamente reconocido. En medicina, su aplicabilidad en la especialidad de otorrinolaringología viene dándose desde hace algunos años. Esto se debe a características tales como su gran resolución (vóxel isotrópico), su baja dosis de radiación, menor tiempo de exposición, además de su costo más bajo en comparación con otras técnicas de imagen (1). En los volúmenes tomográficos, se puede identificar diversas patologías, así como variantes anatómicas, en el macizo facial y en estructuras anatómicas adyacentes (2). Los radiólogos deben brindar información de estas variantes para que el clínico en general y el cirujano en particular pueda prevenir y limitar las complicaciones de tratamiento, así como las intra y postoperatorias (3).

El seno esfenoidal es una estructura de morfología variable, está ubicado en la base central del cráneo y está rodeado por estructuras vitales como la arteria carótida, el nervio óptico y el nervio vidiano $(2,4)$. Se expande en sentido antero posterior y lateral en el cuerpo del hueso esfenoides. Generalmente alcanza su desarrollo completo a los 14 años de edad $(2,4)$.

Es necesario tener conocimiento de la anatomía y las diferentes variantes anatómicas para la comprensión de los procesos patológicos (5). Dentro de las variantes anatómicas más frecuentes, la neumatización de los senos paranasales en general es una de las más comunes. La neumatización del seno esfenoidal en específico, puede extenderse hacia el ala mayor, el proceso pterigoideo, el clivus y en ocasiones hacia el proceso clinoideo anterior (5).

Existen múltiples clasificaciones de la neumatización del seno esfenoidal, siendo la de Hiremath et al. (5) una de las más populares. Ellos clasificaron la extensión del seno esfenoidal en conchal, presellar y sellar (incompleto y completo) (figura 1); la extensión clival en subdorsal, dorsal, occipital y

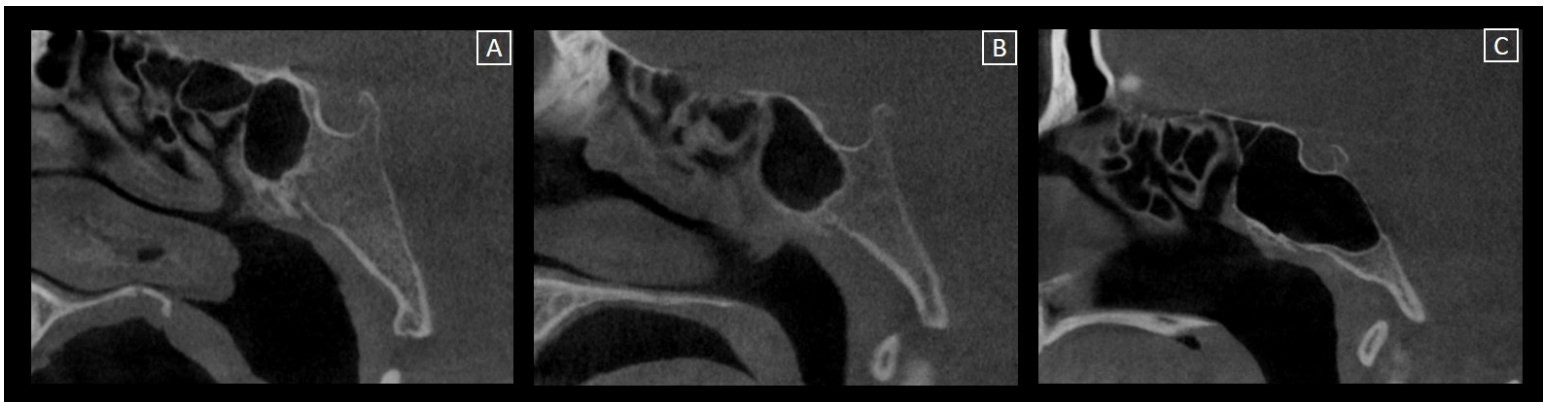

Figura 1. Neumatización del seno esfenoidal. (A) Tipo Conchal; (B) Tipo Sellar Incompleto; (C) Tipos Sellar Completo. Imágenes del archivo del Servicio de Radiología Bucal y Máxilofacial - Centro Dental Docente - FE - UPCH.

\footnotetext{
Facultad de Estomatología, Universidad Peruana Cayetano Heredia. Lima, Perú.

Especialista de Radiología Oral y Maxilofacial

Especialista en Odontología Forense

Magister en Estomatología con mención en Radiología Oral y Maxilofacial

Residente de la Especialidad de Radiología Bucal y Maxilofacial
} 


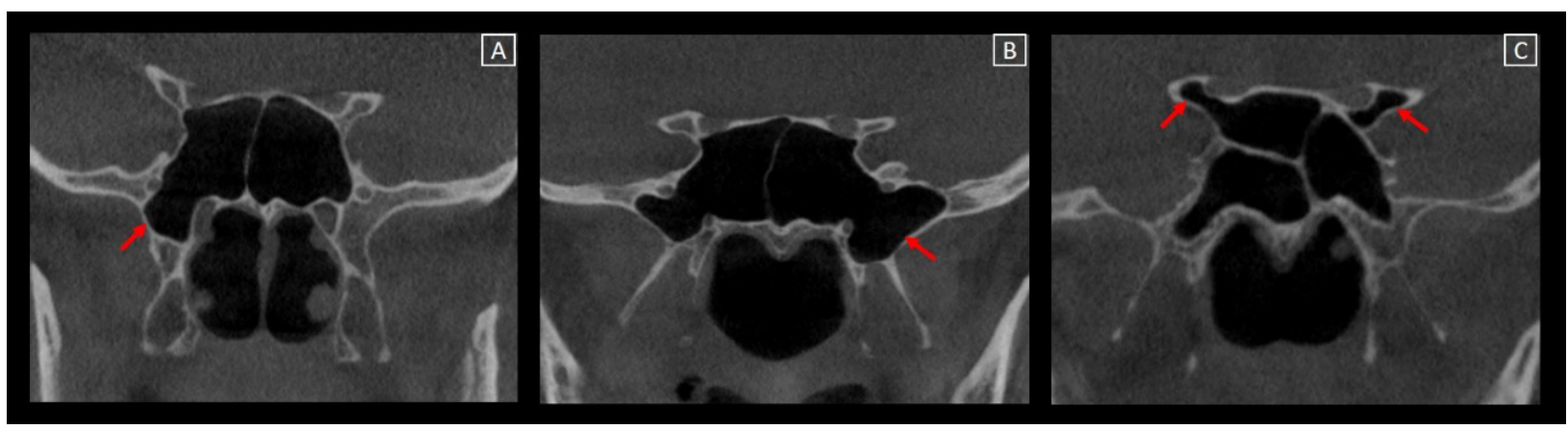

Figura 2. Tipos de extensión lateral y del ala menor. (A) Pterigoides; (B) Lateral Completo; Pterigoides + Ala mayor del esfenoides. (C) Extensión del ala menor. Imágenes del archivo del Servicio de Radiología Bucal y Máxilofacial - Centro Dental Docente - FE - UPCH.

combinado (dorsal + occipital); la extensión lateral en pterigoides, ala mayor del esfenoides y lateral completo (pterigoides + ala mayor del esfenoides); y la extensión del ala menor (figura 2).

Es importante que los cirujanos puedan identificar los límites de esta neumatización ya que varía en cada individuo, para que pueda realizar un buen abordaje endoscópico transesfenoidal y disminuir las complicaciones quirúrgicas (4).

Tener conocimiento de estas variantes también con ayuda en el ámbito forense para reconocer aquellos restos humanos que no se puedan identificar.

Fernando Russbelts Sthorayca Retamozo ${ }^{1, d}$, Milushka Miroslava Quezada Márquez ${ }^{1, a, b, c}$, Vilma Elizabeth Ruiz García de Chacón ${ }^{1, a, c}$

\section{Correspondencia:}

Fernando Russbelts Sthorayca Retamozo

Calle Bolívar 434. Tacna, Perú.

Correo electrónico: fernando.sthorayca@upch.pe

\section{REFERENCIAS BIBLIOGRÁFICAS}

1. Güldner C, Pistorius SM, Diogo I, Bien S, Sesterhenn A, Werner JA. Analysis of pneumatization and neurovascular structures of the sphenoid sinus using cone-beam tomography (CBT). Acta Radiol. 2012; 53(2):214-9. doi: 10.1258/ar.2011.110381

2. Rahmati A, Ghafari R, AnjomShoa M. Normal variations of sphenoid sinus and the adjacent structures detected in cone beam computed tomography. J Dent (Shiraz). 2016; 17(1):32-7.

3. Yilmaz N, Kose E, Dedeoglu N, Colak C, Ozbag D, Durak MA. Detailed anatomical analysis of the sphenoidsinusand sphenoidsinusostiumbycone-beam computed tomography. J Craniofac Surg. 2016;27(6):549-52. doi: 10.1097/SCS.00000 00000002861

4. Tomovic S, Esmaeili A, Chan NJ, et al. Highresolution computed tomography analysis of variations of the sphenoid sinus. J Neurol Surg B Skull Base. 2013;74(2):82-90. doi: 10.1055/s-00331333619

5. Hiremath SB, Gautam AA, Sheeja K, Benjamin G. Assessment of variations in sphenoid sinus pneumatization in Indian population: A multidetector computed tomography study. Indian J Radiol Imaging. 2018; 28(3):273-9. doi: 10.4103/ijri.IJRI_70_18

Recibido: 16/05/2019 